\title{
TU/e EN⿴HONE

\section{Sequential and in situ extraction of furfural from reaction mixture and effect of extracting agents on furfural degradation}

\section{Citation for published version (APA):}

Dietz, C., Verra, M., Verberkt, S., Gallucci, F., Kroon, M., Neira d'Angelo, F., Papaioannou, M., \& van Sint Annaland, M. (2019). Sequential and in situ extraction of furfural from reaction mixture and effect of extracting agents on furfural degradation. Industrial and Engineering Chemistry Research, 58(35), 16116-16125. https://doi.org/10.1021/acs.iecr.9b00694

\section{Document license:}

CC BY-NC-ND

DOI:

10.1021/acs.iecr.9b00694

Document status and date:

Published: 04/09/2019

\section{Document Version:}

Publisher's PDF, also known as Version of Record (includes final page, issue and volume numbers)

\section{Please check the document version of this publication:}

- A submitted manuscript is the version of the article upon submission and before peer-review. There can be important differences between the submitted version and the official published version of record. People interested in the research are advised to contact the author for the final version of the publication, or visit the $\mathrm{DOI}$ to the publisher's website.

- The final author version and the galley proof are versions of the publication after peer review.

- The final published version features the final layout of the paper including the volume, issue and page numbers.

Link to publication

\section{General rights}

Copyright and moral rights for the publications made accessible in the public portal are retained by the authors and/or other copyright owners and it is a condition of accessing publications that users recognise and abide by the legal requirements associated with these rights.

- Users may download and print one copy of any publication from the public portal for the purpose of private study or research.

- You may not further distribute the material or use it for any profit-making activity or commercial gain

- You may freely distribute the URL identifying the publication in the public portal.

If the publication is distributed under the terms of Article 25fa of the Dutch Copyright Act, indicated by the "Taverne" license above, please follow below link for the End User Agreement:

www.tue.nl/taverne

Take down policy

If you believe that this document breaches copyright please contact us at:

openaccess@tue.nl

providing details and we will investigate your claim. 


\section{Sequential and in Situ Extraction of Furfural from Reaction Mixture and Effect of Extracting Agents on Furfural Degradation}

Carin H. J. T. Dietz, ${ }^{\dagger}$ Max Verra, ${ }^{\ddagger}$ Suzanne Verberkt, ${ }^{\ddagger}$ Fausto Gallucci, ${ }^{\dagger}$ Maaike C. Kroon, ${ }^{\S} \|_{\odot}$

Maria F. Neira D’Angelo, ${ }^{\perp \odot}$ Myrto Papaioannou, ${ }^{\perp}$ and Martin van Sint Annaland ${ }^{*},+0$

${ }^{\dagger}$ Inorganic Membrane and Membrane Reactors, Department of Chemical Engineering and Chemistry, Eindhoven University of Technology, P. O. Box 513, 5600 MB Eindhoven, The Netherlands

${ }^{\ddagger}$ Chemical Process Intensification, Department of Chemical Engineering and Chemistry, Eindhoven University of Technology, P. O. Box 513, 5600 MB Eindhoven, The Netherlands

${ }^{\S}$ Petroleum Institute, Chemical Engineering Department, Khalifa University of Science and Technology, P. O. Box 2533, Abu Dhabi, United Arab Emirates

"Center of Catalysis and Separations, Khalifa University of Science and Technology, P.O. Box 2533, Abu Dhabi, United Arab Emirates

${ }^{\perp}$ Chemical Reactor Engineering, Department of Chemical Engineering and Chemistry, Eindhoven University of Technology, P. O. Box 513, 5600 MB Eindhoven, The Netherlands

Supporting Information

ABSTRACT: Furfural is a platform chemical that can be obtained from renewable resources. It can be produced by acid-catalyzed dehydration of xylose. Currently, the furfural yield is relatively low due to side reactions (degradation of furfural). The furfural yield can be improved by rapid and continuous removal of the furfural from the reaction mixture (in situ extraction), preventing further furfural degradation. In this work, the (in situ) extraction of furfural from the reaction mixture using different organic solvents and hydrophobic deep eutectic solvents is investigated. First, the distribution coefficients of furfural in various organic solvents were determined. It was found that extracting agents containing phenol groups showed the highest distribution ratios. Thereafter, the acid-catalyzed degradation of furfural in the presence of the different solvents was assessed. Addition of organic solvents or hydrophobic deep eutectic solvents resulted in a significant decrease in furfural degradation compared to the blank and the benchmark. Finally, in situ extraction with the different extracting agents was performed. The xylose conversion was not influenced by solvent addition, whereas the furfural yields were significantly higher compared to the blank experiment, even when low amounts of extracting agents were applied. This was explained by the limited co-extraction of the acid to the organic phase, preventing further contact/reaction between the furfural and the acid. Hence, organic solvents and hydrophobic deep eutectic solvents can be promising in situ extracting agents for the removal of furfural from biorefinery processes.

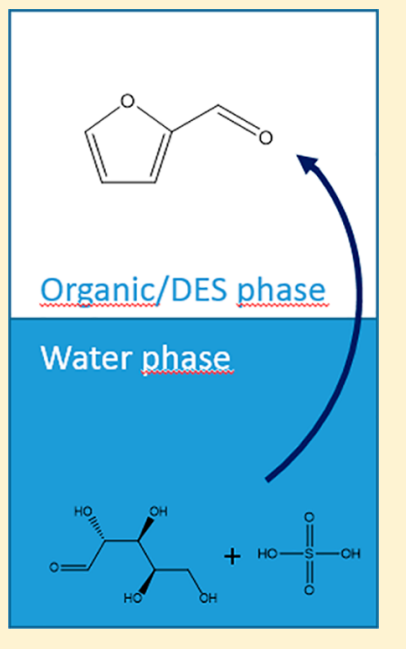

\section{INTRODUCTION}

The development of novel "green" materials, biofuels as well as sustainable chemicals moves toward more ecofriendly and cost-efficient production processes and technologies. The main reasons for developing biorefining processes are the depletion of fossil resources and the reduction in the emissions of carbon dioxide and other greenhouse gases. However, the cost of processing renewables to chemicals and fuels is often too high to be economically feasible. This is partly due to the fact that traditional synthesis routes that were developed and optimized for hydrocarbons are not easily adapted for the use of renewables. ${ }^{1}$ Moreover, biomass is a more complex raw material requiring additional purification and separation steps.

Lignocellulosic biomass is a promising alternative to nonrenewable resources for the sustainable supply of fuels and chemicals in the future. ${ }^{2,3}$ The hydrolysis of lignocellulose has recently been mentioned to be the most important entry point into a biorefinery. ${ }^{4}$ Already in 1920, the first acid hydrolysis of lignocellulose was developed. ${ }^{5}$ Most important products are glucose (by hydrolysis of cellulose), xylose (by hydrolysis of hemicellulose), and phenols (by hydrolysis of lignin). ${ }^{6}$ These products can be further converted into useful building blocks for the chemical industry, such as furfural, hydroxymethylfurfural, levulinic acid, and glycols. ${ }^{7,8}$ This work focuses on the production of furfural from lignocellulose.

Special Issue: Biorenewable Energy and Chemicals

Received: February 3, 2019

Revised: April 1, 2019

Accepted: April 5, 2019

Published: April 5, 2019 
Table 1. Chemicals Used, Including Purity, Source, CAS Number, Structure Formula, and Melting Point $\left(T_{\mathrm{m}}\right)$ (As Provided by the Supplier)

\begin{tabular}{|c|c|c|c|c|c|c|}
\hline name & abbreviation & $\begin{array}{l}\text { purity } \\
\text { (wt \%) }\end{array}$ & source & $\begin{array}{l}\text { CAS Reg. } \\
\text { No. }\end{array}$ & $T_{\mathrm{m}}(\mathrm{K})$ & structure formula \\
\hline decanoic acid & deca & $>98$ & Sigma-Aldrich & $334-48-5$ & $300-305$ & $\mathrm{CH}_{3}\left(\mathrm{CH}_{2}\right)_{8} \mathrm{COOH}$ \\
\hline furfural & FF & $>99$ & Sigma-Aldrich & $98-01-1$ & 237 & $\mathrm{C}_{5} \mathrm{H}_{4} \mathrm{O}_{2}$ \\
\hline thymol & thy & $>99$ & TCI Chemicals & $89-83-8$ & $322-325$ & $\left\{\left[\left(\mathrm{CH}_{3}\right)_{2} \mathrm{CH}\right] \mathrm{C}_{6} \mathrm{H}_{3}\right\}_{2}\left\{\left(\mathrm{CH}_{3}\right) \mathrm{OH}\right\}_{5}$ \\
\hline menthol & men & $>99$ & TCI Chemicals & $15356-60-2$ & 304 & $\mathrm{C}_{10} \mathrm{H}_{20} \mathrm{O}$ \\
\hline lidocaine & lid & $>99$ & Sigma-Aldrich & $137-58-6$ & $339-342$ & $\mathrm{C}_{14} \mathrm{H}_{22} \mathrm{~N}_{2} \mathrm{O}$ \\
\hline D-xylose & xylose & $>98$ & TCI Chemicals & $56-86-6$ & & $\mathrm{C}_{5} \mathrm{H}_{10} \mathrm{O}_{5}$ \\
\hline sulfuric acid & & $>99$ & TCI Chemicals & $7664-93-9$ & & $\mathrm{H}_{2} \mathrm{SO}_{4}$ \\
\hline carvacrol & car & $>98$ & TCI Chemicals & $499-75-2$ & 276 & $\left(\mathrm{CH}_{3}\right)_{2} \mathrm{CHC}_{6} \mathrm{H}_{3}\left(\mathrm{CH}_{3}\right) \mathrm{OH}$ \\
\hline 2-sec-butylphenol & $2 \mathrm{sec}$ & $>98$ & TCI Chemicals & $89-72-5$ & 263 & $\mathrm{C}_{2} \mathrm{H}_{5} \mathrm{CH}\left(\mathrm{CH}_{3}\right) \mathrm{C}_{6} \mathrm{H}_{4} \mathrm{OH}$ \\
\hline toluene & tol & $>99$ & TCI Chemicals & $108-88-3$ & & $\mathrm{C}_{6} \mathrm{H}_{5} \mathrm{CH}_{3}$ \\
\hline 2-adamantanol & 2ada & $>98$ & TCI Chemicals & $700-57-2$ & & $\mathrm{C}_{10} \mathrm{H}_{16} \mathrm{O}$ \\
\hline cinnamyl alcohol & $\operatorname{cin}$ & $>98$ & TCI Chemicals & $4407-36-7$ & 306 & $\mathrm{C}_{6} \mathrm{H}_{5} \mathrm{CH}=\mathrm{CHCH}_{2} \mathrm{OH}$ \\
\hline camphor & cam & $>96$ & Sigma-Aldrich & $76-22-2$ & 448 & $\mathrm{C}_{10} \mathrm{H}_{16} \mathrm{O}$ \\
\hline citronellol & cit & $>95$ & TCI Chemicals & $7540-51-4$ & & $\begin{array}{l}\left(\mathrm{CH}_{3}\right)_{2} \mathrm{C}=\mathrm{CHCH}_{2} \mathrm{CH}_{2} \mathrm{CH}\left(\mathrm{CH}_{3}\right) \\
\mathrm{CH}_{2} \mathrm{CH}_{2} \mathrm{OH}\end{array}$ \\
\hline 2-ethylphenol & 2et & 99 & Sigma-Aldrich & $90-00-6$ & 255 & $\mathrm{C}_{2} \mathrm{H}_{5} \mathrm{C}_{6} \mathrm{H}_{4} \mathrm{OH}$ \\
\hline 2-propylphenol & 2 pro & 98 & Sigma-Aldrich & $644-35-9$ & & $\mathrm{CH}_{3} \mathrm{CH}_{2} \mathrm{CH}_{2} \mathrm{C}_{6} \mathrm{H}_{4} \mathrm{OH}$ \\
\hline 4-ethylphenol & 4et & $>98$ & Sigma-Aldrich & $123-07-9$ & 313 & $\mathrm{C}_{2} \mathrm{H}_{5} \mathrm{C}_{6} \mathrm{H}_{4} \mathrm{OH}$ \\
\hline 2,6-diisopropylphenol & 26diiso & $>97$ & Sigma-Aldrich & $2078-54-8$ & 291 & {$\left[\left(\mathrm{CH}_{3}\right)_{2} \mathrm{CH}\right]_{2} \mathrm{C}_{6} \mathrm{H}_{3} \mathrm{OH}$} \\
\hline 4-sec-butyl-2,6-diisobutylphenol & $4 s$ & 96 & Sigma-Aldrich & $17540-75-9$ & 298 & $\mathrm{C}_{2} \mathrm{H}_{5} \mathrm{CH}\left(\mathrm{CH}_{3}\right) \mathrm{C}_{6} \mathrm{H}_{2}\left[\mathrm{C}\left(\mathrm{CH}_{3}\right)_{3}\right]_{2} \mathrm{OH}$ \\
\hline 2,4-di-tert-butylphenol & 24ditert & 99 & Sigma-Aldrich & $96-76-4$ & 328 & {$\left[\left(\mathrm{CH}_{3}\right)_{3} \mathrm{C}\right]_{2} \mathrm{C}_{6} \mathrm{H}_{3} \mathrm{OH}$} \\
\hline 2,6-di-tert-butylphenol & 26ditert & 99 & Sigma-Aldrich & $128-39-2$ & 308 & {$\left[\left(\mathrm{CH}_{3}\right)_{3} \mathrm{C}\right]_{2} \mathrm{C}_{6} \mathrm{H}_{3} \mathrm{OH}$} \\
\hline
\end{tabular}

Furfural is a key derivative used for the production of a wide range of important chemicals, including pharmaceuticals and phenolic resins, as well as an intermediate for lubricants, nylon, adhesives, plastics, and solvents. ${ }^{9-12}$

Furfural is mainly obtained by the dehydration of xylose in the presence of an acidic catalyst at high temperatures. ${ }^{11,13-16}$ However, furfural yields are still relatively low. Subsequent reactions between furfural and its precursors are the primary cause of these low yields. ${ }^{17-23}$ Higher yields can be achieved by rapid and continuous removal of furfural from the aqueous reaction mixture.

Conventionally, liquid-liquid extraction is used for the recovery of furfural. If this extraction step could be carried out simultaneously with the reaction (i.e., in situ extraction), ${ }^{17}$ then undesired side reactions (further conversion/degradation of furfural to humins) can be prevented. In that case, the dehydration of xylose to furfural should be carried out in the presence of an immiscible solvent, so that most of the furfural can be transferred from the aqueous (reaction) phase to the solvent (extraction) phase almost immediately after it is formed, preventing any further degradation of the furfural. Thereafter, the furfural can be recovered from the solvent by simple binary distillation.

The suggested process for in situ extraction of furfural from its reaction mixture requires the selection of an appropriate solvent. Suitable solvents should be water-immiscible and thermally and acid stable (dehydration conditions) and show a high furfural distribution coefficient. Very recently, hydrophobic bio-based deep eutectic solvents (DESs) were discovered, which are combinations of two or more solids (e.g., menthol, thymol, or lidocaine), which liquefy at room temperature upon mixing due to attractive interactions. ${ }^{18}$ These hydrophobic DESs were found to show high distribution coefficients for furfural and very low water solubilities. ${ }^{17,19}$ Therefore, hydrophobic DESs are expected to be promising solvents for in situ extraction of furfural from its reaction mixture. However, the effect of hydrophobic DESs on the prevention of furfural degradation has never been investigated before.

In this study, 15 hydrophobic volatile organic solvents were evaluated as furfural extracting agents first. The furfural distribution coefficients were experimentally determined, and a relationship between the structure of the solvent and the obtained distribution coefficient was established. Two extracting agents with the highest distribution coefficients (i.e., carvacrol and 2-sec-butylphenol), as well as two solid chemicals that interact with furfural (i.e., thymol and menthol) and a benchmark (i.e., toluene), were selected to determine the behavior of the degradation reaction of furfural to humins at five different acid concentrations $(0,10,20,30$, and 40 wt \%) and at three different temperatures (335, 383, and $413 \mathrm{~K}$ ). Also, the effect of the acid concentration and temperature on the conversion of xylose (with an initial concentration of $4 \mathrm{wt}$ $\%)$ to furfural was experimentally determined. The best reaction conditions were determined and selected (4 wt \% xylose, 20 wt $\% \mathrm{H}_{2} \mathrm{SO}_{4}$, and $403 \mathrm{~K}$ ) to investigate the influence of the selected extracting agents on the xylose conversion and the furfural yield. Finally, four hydrophobic DESs (decanoic acid-menthol (1:1), decanoic acid-thymol (1:1), thymollidocaine (2:1), and thymol-menthol (1:2)), which were selected on the basis of their molecular structure, viscosity, distribution coefficient for furfural, and selectivity for acid, were tested as in situ extracting agents to reduce the degradation of furfural during the integrated process (combined reaction and in situ extraction).

\section{EXPERIMENTAL SECTION}

Chemicals. In Table 1 the chemicals used in this work, including their purities and sources, are presented. All chemicals were used without further purification.

Extraction Measurements. The extraction of furfural (FF) with the 15 solvents was measured using a 1 wt \% FF (as 
starting concentration) solution in water. In a $50 \mathrm{~mL}$ centrifuge tube, $10 \mathrm{~g}$ of these aqueous solutions and different amounts of solvent (different solvent-to-feed ratios, 10:1, 5:1, 1:1, and 1:2 molar ratio) were added and mixed in a shake machine (IKA KS 4000i) during $2 \mathrm{~h}$ at $500 \mathrm{rpm}$ at the selected temperature (i.e., 298 and $323 \mathrm{~K}$ ). To separate the solvents from the aqueous phase, the tubes were centrifuged (Sigma 2-16KL) for $30 \mathrm{~min}$ with a speed of $8000 \mathrm{rpm}$ at a temperature of $298 \mathrm{~K}$. To obtain the concentration of FF, a sample of the aqueous phase was taken $( \pm 1 \mathrm{~mL})$ and analyzed using high-performance liquid chromatography (HPLC).

HPLC Analyses. The concentrations of FF and xylose were measured with an HPLC Agilent Technology 1260 Infinity Series instrument (Agilent Technologies, Santa Clara, CA, USA), which made use of MetaCarb 67C Guard cartridges; a MetaCarb 67C analytical column operating at a temperature of $353 \mathrm{~K}$; a $\mathrm{G} 1311 \mathrm{~B}$ isocratic pump operating at a pump flow rate of $0.400 \mathrm{~mL} \mathrm{~min}{ }^{-1}$; a $\mathrm{G} 1314 \mathrm{~A}$ variable wavelength detector (VWD) with a zero offset of $5 \%$, an attenuation of $1000 \mathrm{mAU}$, and a wavelength of $254 \mathrm{~nm}$; and a G1362A refractive index detector (RID) with a zero offset of $5 \%$, a positive signal polarity, and an operation temperature of $308 \mathrm{~K}$. The sample volume was $1.0 \mu \mathrm{L}$, and run time was 50 min per sample. A chromatogram and the calibration curve are plotted in the Supporting Information (Experimental S1).

Degradation Experiments. Two extraction solvents with the highest distribution coefficients (car and 2sec), two solid chemicals that have an interaction with furfural (thy and men), and a benchmark (tol) were selected to determine the behavior of the deconstructive reaction of furfural. Samples of $10 \mathrm{~g}$ amounts of 1 wt \% FF in different acid concentration $(0,10$, 20 , and $40 \mathrm{wt} \%: 0,1.8,3.7$, and $7.3 \mathrm{M}$ ) solutions were put in $20 \mathrm{~mL}$ vials, and different amounts of solvent (different solvent-to-feed ratios) were added. The vials were heated to 335,383 , and $413 \mathrm{~K}$ and at different times $(0,10,15,30,45$, and $60 \mathrm{~min}$ ), and thereafter the vials were cooled to $273 \mathrm{~K}$ to stop the degradation. All experiments were done in duplicate. The concentrations of FF and xylose of the sample of the water phase were measured with HPLC, and a sample of the organic phase was measured with GC-MS.

GC-MS Analyses. The concentration of FF in the organic phase was measured with a GSMC-QP2010 SE setup, made by Shimadzu. This setup is equipped with an AOC-20i autoinjector, a CP-Sil 5 CB Agilent J7W GC column with length of $50 \mathrm{~m}$, diameter of $0.32 \mathrm{~mm}$, and thickness of $1.20 \mu \mathrm{m}$, a GC column oven temperature of $393 \mathrm{~K}$ and injection temperature of $523 \mathrm{~K}$, linear velocity of $40.4 \mathrm{~cm} / \mathrm{s}$, a column pressure of

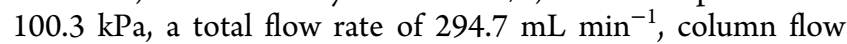
rate of $1.93 \mathrm{~mL} \mathrm{~min}^{-1}$, and a split ratio of 150.0; the MS has an ion temperature of $473 \mathrm{~K}$, an interface temperature of $523 \mathrm{~K}$, and a scan speed of 3333. A chromatogram of FF and the calibration curve for FF are plotted in the Supporting Information (Experimental S2).

Xylose to Furfural Reaction Experiments. The acidcatalyzed reaction of xylose to $\mathrm{FF}$ is performed in $20 \mathrm{~mL}$ vials equipped with metal caps with a septum in them. A $10 \mathrm{~g}$ amount of 4 wt $\%$ xylose solution with different acid concentrations $(0,10,20$, and $40 \mathrm{wt} \%)$ were put in each 20 $\mathrm{mL}$ vial, and different amounts of solvent (different solvent-tofeed ratios) were added. The vials were heated with an IKA RCT basic heater equipped with an IKA ETS-D6 controller to various temperatures $(353,383,403$, and $423 \mathrm{~K})$, and after different times $(0,10,15,30,45$, and $60 \mathrm{~min})$ the vials were cooled to $273 \mathrm{~K}$ to stop the reaction. To measure the concentration of xylose and FF a sample of the water phase was measured with HPLC and a sample of the organic phase was measured with GC-MS to obtain the FF concentration. All experiments were done at least in duplicate.

In Situ Extraction Experiments. The effect of the five extraction agents (men, thy, car, 2sec, and tol) on the extraction process during reaction was studied at the most optimal reaction conditions. Samples of $10 \mathrm{~g}$ each of $4 \mathrm{wt} \%$ xylose in $20 \mathrm{wt} \% \mathrm{H}_{2} \mathrm{SO}_{4}$ solution were put in $20 \mathrm{~mL}$ vials, and the solvent was added in the solvent-to-feed molar ratio of 5:1. The vials were heated with an IKA RCT basic heater equipped with an IKA ETS-D6 thermometer to $403 \mathrm{~K}$, and after different times $(0,10,15,30,45$, and $60 \mathrm{~min})$ the vials were immediately cooled to $273 \mathrm{~K}$ to stop the reaction. A sample of the water phase was measured with HPLC, and a sample of the organic phase was measured with GC-MS. All experiments were done in duplicate.

Yield Predictions. Yields for FF in the presence of different in situ extracting agents were predicted on the basis of the distribution coefficients obtained from the extraction experiments (without reaction) and the blank reaction experiment (without addition of any extracting agent). A set of modeling equations was derived from the mole balances of the main components (i.e., xylose and FF) and two liquid phases (i.e., water and organic solvent/DES) and solved numerically using MATLAB (see the Supporting Information, Experimental S3). This model assumes an ideally stirred batch reactor, a mass transfer coefficient of $0.1 \mathrm{~s}^{-1}$ (a standard value for a well-stirred system ${ }^{23}$ ), and the kinetic mechanism reported by Weingarten et al. ${ }^{24}$ Note that this kinetic model was obtained by empirical fittings using $0.1 \mathrm{M} \mathrm{HCl}$, i.e., significantly lower acid concentrations than those used in this work $\left(0-40\right.$ wt $\left.\% \mathrm{H}_{2} \mathrm{SO}_{4}\right)$. In the absence of literature data for higher acid concentrations, we have assumed a linear dependence of all reaction rates with respect to the concentration of protons, thus limiting the validity of our predictions to qualitative trends. A quantitative prediction of the system performance lays outside the scope of this work.

DESs Preparation. The four different hydrophobic DESs prepared in this work, including their hydrogen bond donors (HBDs), hydrogen bond acceptors (HBAs), and the ratio between the HBD and HBA, are presented in Table 2. In a

Table 2. DESs Prepared in This Work Including Their HBDs and HBAs, HBD:HBA Ratio, and Abbreviation

\begin{tabular}{clcl}
\multicolumn{1}{c}{ HBD } & HBA & molar ratio & abbreviation \\
decanoic acid & thymol & $1: 1$ & deca-thy \\
decanoic acid & menthol & $1: 1$ & deca-men \\
thymol & lidocaine & $2: 1$ & thy-lid \\
thymol & menthol & $1: 2$ & thy-men \\
\hline
\end{tabular}

round-bottom flask, both solids (HBD and HBA) were weighed in the desired molar ratio, stirred, and heated in an oil bath at $313 \mathrm{~K}$ for $2 \mathrm{~h}$ to obtain an approximate amount of $100 \mathrm{~g}$ of a liquid (DES), which stayed liquid after cooling to room temperature.

\section{RESULTS AND DISCUSSION}

Extraction of FF Using 15 Organic Solvents. The distribution coefficient $(K)$ is an important parameter for liquid-liquid extraction. ${ }^{19}$ It is the ratio between the mole 
Table 3. Distribution Coefficient of FF Obtained by Extraction with 15 Different Solvents at 298 and $328 \mathrm{~K}$ and $1.01 \mathrm{bar}$ from a Starting Solution Consisting of 1 wt \% FF at Different Solvent-to-Feed Ratios ${ }^{a}$

\begin{tabular}{|c|c|c|c|c|c|c|c|c|c|}
\hline Temp & & & 298 & & & & 328 & & \\
\hline mol ratio & & $20: 1$ & $10: 1$ & $2: 1$ & $1: 1$ & 20:1 & 10:1 & $2: 1$ & $1: 1$ \\
\hline Solvent & Structure & & & & & & & & \\
\hline tol & & 3 & 5 & 2 & 0 & 3 & 5 & 4 & 5 \\
\hline $2 \mathrm{sec}$ & & 44 & 67 & 41 & 28 & 34 & 53 & 38 & 28 \\
\hline thy & & & & & & 30 & 40 & 44 & 30 \\
\hline 2 pro & & 30 & 45 & 33 & 37 & 30 & 40 & 22 & 25 \\
\hline $2 \mathrm{et}$ & & 30 & 45 & 34 & 37 & 30 & 46 & 48 & 10 \\
\hline car & & 27 & 46 & 27 & 37 & 27 & 46 & 41 & 42 \\
\hline 26di iso & & 30 & 30 & 36 & 28 & 21 & 36 & 28 & 18 \\
\hline 24 di tert & & 1 & 3 & 20 & 47 & 5 & 11 & 39 & 28 \\
\hline $4 \mathrm{sec}$ & & 4 & 10 & 8 & 5 & 5 & 8 & 8 & 5 \\
\hline cit & & 37 & 7 & 2 & 3 & 3 & 4 & 4 & 5 \\
\hline $26 \mathrm{di}$ tert & & & 0 & & & & 0 & & \\
\hline cam & & & 0 & & & & 0 & & \\
\hline $2 \mathrm{ada}$ & & & 0 & & & & 0 & & \\
\hline $\operatorname{cin}$ & & & 0 & & & & 0 & & \\
\hline men & & & & & & & 0 & & \\
\hline
\end{tabular}

${ }^{a}$ Standard uncertainties are $u(T)=1 \mathrm{~K}, u(p)=0.03$ bar, and $u(K)=2$.

fraction of the solute in the solvent (or extract) phase, $x_{\mathrm{E}}$, and the mole fraction of the solute in the water (raffinate) phase, $x_{\mathrm{R}}$, when in equilibrium:

$$
K=\frac{x_{\mathrm{E}}}{x_{\mathrm{R}}}
$$

In this work, the solute concentrations used are low $(\sim 1 \%)$ and operation takes place at constant solvent-to-feed ratios. Therefore, the solvent and feed streams can be assumed to be constant and identical, and eq 1 can be approximated with (eq 2): 

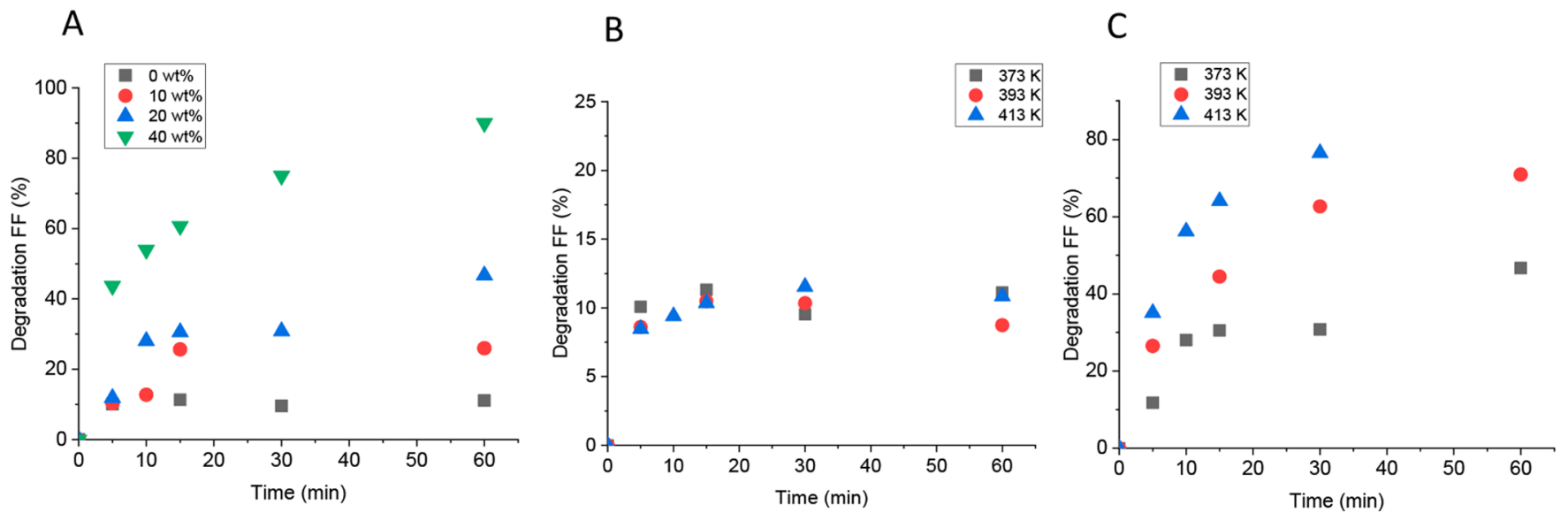

Figure 1. FF degradation (\%) in time: (a) at $373 \mathrm{~K}$ and different acid concentrations (0, 10, 20, and $40 \mathrm{wt} \%)$, (b) at 0 wt \% acid concentration and different temperatures $(373,393$, and $413 \mathrm{~K})$, and (c) at $20 \mathrm{wt} \%$ acid concentration and different temperatures $(373,393$, and $413 \mathrm{~K})$.

$$
K \approx \frac{C_{0}-C_{\mathrm{R}}}{C_{\mathrm{R}}}\left(\frac{M_{\mathrm{f}}}{M_{\mathrm{s}}}\right)
$$

where $C_{0}$ is the concentration of the solute in the feed stream and $C_{\mathrm{R}}$ is the concentration of the solute in the raffinate stream, $M_{\mathrm{f}}$ is the mass of the feed phase, and $M_{\mathrm{s}}$ is the mass of the solvent phase.

The extraction of the pure component FF using 15 different extraction solvents was performed in order to study the effect of the chemical structure on the extraction performance. The 15 different extraction solvents were selected on the basis of their chemical structure. The selected solvents either contain $\mathrm{OH}$ groups (allowing hydrogen bonding), and/or benzyl groups with different functional side groups (resulting in steric hindrance). Also, the effects of the temperature and the solvent-to-feed ratio were studied. All distribution coefficients obtained are shown in Table 3. Some distribution coefficients have not been measured. One reason is that the extracting agent should be in the liquid phase, otherwise one cannot perform liquid-liquid extraction, but men (melting point is $304 \mathrm{~K}^{25}$ ) and thy (melting point is $324 \mathrm{~K}^{25}$ ) are solids at 298 $\mathrm{K}$ and are therefore not included in Table 3. Also, the distribution coefficients of 26tert, cam, 2ada, and cin were not determined at solvent-to-feed ratios other than 5:1, as their values at the 5:1 ratio were too low to be useful as extracting agents.

From Table 3 the following four observations can be made: (i) an $\mathrm{OH}$ group, (ii) a benzyl group, (iii) an $\mathrm{OH}$ group on the benzyl group, and (iv) less and smaller side groups lead to higher distribution coefficients. Thus, phenol (containing both an $\mathrm{OH}$ group and a benzyl group, and no other side groups) would be the best extracting agent. However, phenol is also a high-risk solvent that should be avoided in "green" processing. Therefore, the best extracting agents have structures comparable to that of phenol, but without the disadvantages. In this study the best performing extracting agents were $2 \mathrm{sec}$, 2et, car, thy, 2pro, and 26diiso.

The effect of the temperature on the extraction performance was found to be limited. This is consistent with previous observations showing that the temperature is not a significant factor influencing the FF extraction coefficient. ${ }^{26}$ However, the solvent-to-feed ratio does have a significant influence on the obtained extraction coefficients, as different compositions of extract and raffinate phases are achieved when different solvent-to-feed ratios are applied, with the highest values obtained for a ratio of 10:1 (=10 mol car: $1 \mathrm{~mol} \mathrm{FF}=1.5 \mathrm{~g}$ car:10 g water/acid/xylose). Thus, the solvent-to-feed mole ratio is a subject of optimization. As expected, higher values result in higher extraction coefficients. The interactions between FF with the organic solvent, i.e., the activity coefficient of FF in the organic solvent (which is most influenced by changing the organic solvent/water ratio) is the most important factor determining the observed distribution ratios.

Degradation of FF. Degradation at Different Reaction Conditions. The concentration of FF in the water phase (without addition of any solvent, a blank experiment) as a function of time has been measured at different temperatures $(373,393$, and $413 \mathrm{~K})$ and different acid concentrations $\left(\mathrm{H}_{2} \mathrm{SO}_{4}, 0,10,20\right.$, and 40 wt $\left.\%\right)$. The degradation was determined as the ratio of the amount of FF lost/converted over the initial amount of FF. Figure 1 shows the degradation results of FF (a) at one temperature $(373 \mathrm{~K})$ and four different acid concentrations and (b) at one acid concentration (20 wt $\%)$ and three different temperatures. All other degradation results can be found in the Supporting Information (Figures S1-S5).

As expected, the FF degradation increases with increasing acid concentration and with increasing temperature. However, when no acid is added, two interesting observations can be made: (i) the temperature effect $(373,393$, and $413 \mathrm{~K})$ is insignificant, and (ii) the FF degradation is constant at approximately $10 \%$ after $5 \mathrm{~min}$ (no degradation measured at the starting time). This can only be explained by the occurrence of two different degradation mechanisms., ${ }^{9,16}$

Degradation in the Presence of Different Extracting Agents. Two extracting agents with the highest distribution coefficients (i.e., car and 2sec), as well as two solid chemicals that interact with FF (i.e., thy and men) and a benchmark (i.e., tol), were selected to determine the effect of the extracting agent on the FF degradation at different acid concentrations $(0,10,20$, and $40 \mathrm{wt} \%)$, different temperatures $(335,383$, and $413 \mathrm{~K})$ at a solvent-to-feed ratio of 10:1. It should be noticed that men and thy become liquid upon mixing with FF in certain ratios (i.e., deep eutectic solvent formation). Outside the liquid region, FF concentrations could not be determined and therefore degradation results at these conditions are not included. 
In Figure 2 the results for the degradation of FF at $393 \mathrm{~K}$ and $10 \mathrm{wt} \%$ acid are plotted as a function of time. All other

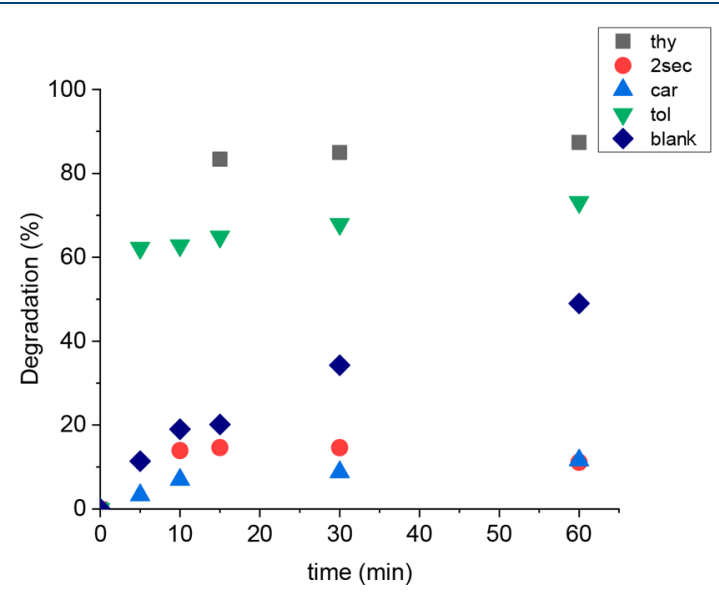

Figure 2. FF degradation (\%) in time at $393 \mathrm{~K}$ and $10 \mathrm{wt} \%$ acid concentration in the presence of different extracting agents (with thy, 2 sec, car, and tol and without solvent (blank)).

graphs (at different acid concentrations and at different temperatures) can be found in the Supporting Information (Figures S6-S30).

From Figure 2 it can be concluded that the degradation of FF in the absence of any extracting agent is increasing in time. This is explained by the fact that the FF is in continuous contact with the acid (catalyst for degradation) in the water phase. However, in the presence of an extracting agent, the degradation of FF does not continuously increase in time but reaches a plateau after about $10 \mathrm{~min}$. This can be explained by the transfer of the FF from the (acidic) water phase to the (non-acidic) organic phase, where the FF is no longer in contact with the acid, and thus the degradation reaction, which is acid-catalyzed, comes to a halt. Furthermore, it can be noticed that the degradation of FF in the presence of car and $2 \mathrm{sec}$ is much lower than in the presence of tol and thy. An explanation could be the fact that the acid is co-extracted in the case of tol and thy, while it is not co-extracted when car or $2 \mathrm{sec}$ is added as extracting agent. This hypothesis was tested by measuring the $\mathrm{pH}$ ( $\mathrm{pH}$ indicator test strips) of both phases (water phase + organic phase) after extraction of FF at $328 \mathrm{~K}$ and a $20 \mathrm{wt} \%$ acid concentration using thy, tol, car, and 2sec; see Table 4. Indeed, the $\mathrm{pH}$ of the tol (and thy) phase decreased to 4 after contact with the acidic water phase, while the pHs of car and $2 \mathrm{sec}$ stayed at 7. Thus, it seems that coextraction of the acid takes place when tol (and thy) are used as extracting agents, and therefore the FF degradation reaction proceeds in the organic phase. But when car and $2 \mathrm{sec}$ are used

Table 4. $\mathrm{pH}$ of the Organic and Water Phase with Different Extracting Agents at $328 \mathrm{~K}$, with $20 \mathrm{wt} \%$ acid, and at 1.01 bar from a Starting Solution Consisting of 1 wt \% FF ${ }^{a}$

\begin{tabular}{ccc} 
& \multicolumn{2}{c}{$\mathrm{pH}$} \\
\cline { 2 - 3 } compound & organic phase & water phase \\
thy & 4 & 1 \\
tol & 4 & 1 \\
car & 7 & 1 \\
$2 \mathrm{sec}$ & 7 & 1
\end{tabular}

${ }^{a}$ Standard uncertainties are $u(T)=1 \mathrm{~K}$ and $u(p)=0.03$ bar. as extracting agents, the acid is not co-extracted and the FF degradation reaction stops in the organic phase.

Reaction of Xylose to FF. Determination of Optimum Reaction Conditions. The effect of the acid concentration and temperature on the conversion and yield of the reaction of xylose to FF has been determined experimentally as a function of reaction time. The conversion of xylose and the yield of FF were obtained at six different acid concentrations $(1,5,10,20$, 30 , and $40 \mathrm{wt} \% \mathrm{H}_{2} \mathrm{SO}_{4}$ ) and four different temperatures (353, 383,403 , and $423 \mathrm{~K}$ ) at a starting concentration of xylose of 4 wt $\%$ in water. It should be noted that not all combinations were measured: (i) at $353 \mathrm{~K}$ the conversion and yield at low acid concentrations were too low to be determined (below the detection limit), while (ii) at 403 and $423 \mathrm{~K}$ and at high acid concentrations the degradation of FF into humins was too pronounced (forming a black suspension), so that it became impossible to measure conversions and yield.

The conversion of xylose and the yield of FF versus reaction time at different acid concentrations are plotted in Figures 3 and 4 at temperatures of 383 and $403 \mathrm{~K}$, respectively. The conversions and yields at the other investigated temperatures ( 353 and $423 \mathrm{~K}$ ) can be found in the Supporting Information, Figures S31-S34.

From Figures 3 and 4, it can be concluded that the highest conversions and yields are obtained at $383 \mathrm{~K}$ and $40 \mathrm{wt} \%$ acid. However, at these conditions we already noticed some humin formation (formation of black particles). The next best conversion and yield were obtained at $403 \mathrm{~K}$ and $20 \mathrm{wt} \%$, where humin formation was not prevailing. The yield and conversion could be increased with longer reaction times, but also the degradation will be increased. It is also more advantageous to work at $403 \mathrm{~K}$ and $20 \mathrm{wt} \%$ over working at $383 \mathrm{~K}$ and 40 wt \% because of the lower sulfuric acid requirement. This will save on material cost and is more environmentally benign, although the energy cost will be slightly higher. Despite that, the acid is used as a catalyst and the recovery and reusability are important. Thus, the optimized reaction conditions for the reaction of xylose to $\mathrm{FF}$ were found to be $4 \mathrm{wt} \%$ xylose, $20 \mathrm{wt} \% \mathrm{H}_{2} \mathrm{SO}_{4}$, and $403 \mathrm{~K}$. These conditions were used in the subsequent in situ extraction experiments.

In Situ Extraction of FF with Organic Extracting Agents. The solvents selected for the degradation experiments (car, $2 \mathrm{sec}$, men, thy, and tol) were also applied as in situ extracting agents for the removal of FF during xylose conversion at the optimized reaction conditions (4 wt $\%$ xylose, 20 wt $\% \mathrm{H}_{2} \mathrm{SO}_{4}$, and $403 \mathrm{~K}$ ). Again, the conversion of xylose and the yield of FF were determined during in situ extraction at a solvent-to-feed molar ratio of 10:1 (see Extraction of FF Using 15 Organic Solvents).

The conversion of xylose and the yield of FF versus reaction time in the presence of different in situ extracting agents are presented in Figure 5a,b, respectively. Figure 5a shows that the conversion of xylose is not significantly affected by the addition of the in situ extracting agent. Apparently, the xylose stays in the water phase, where the reaction occurs, and is not extracted to the organic phase. This is consistent with previous observations that sugars (including xylose) do not dissolve in these organic extracting agents. ${ }^{27}$

On the contrary, the yield to FF is strongly dependent on the addition of the in situ extracting agent (see Figure 5b): high FF yields are obtained in the presence of $2 \mathrm{sec}$, car, and thy, while low FF yields are obtained in the presence of men 

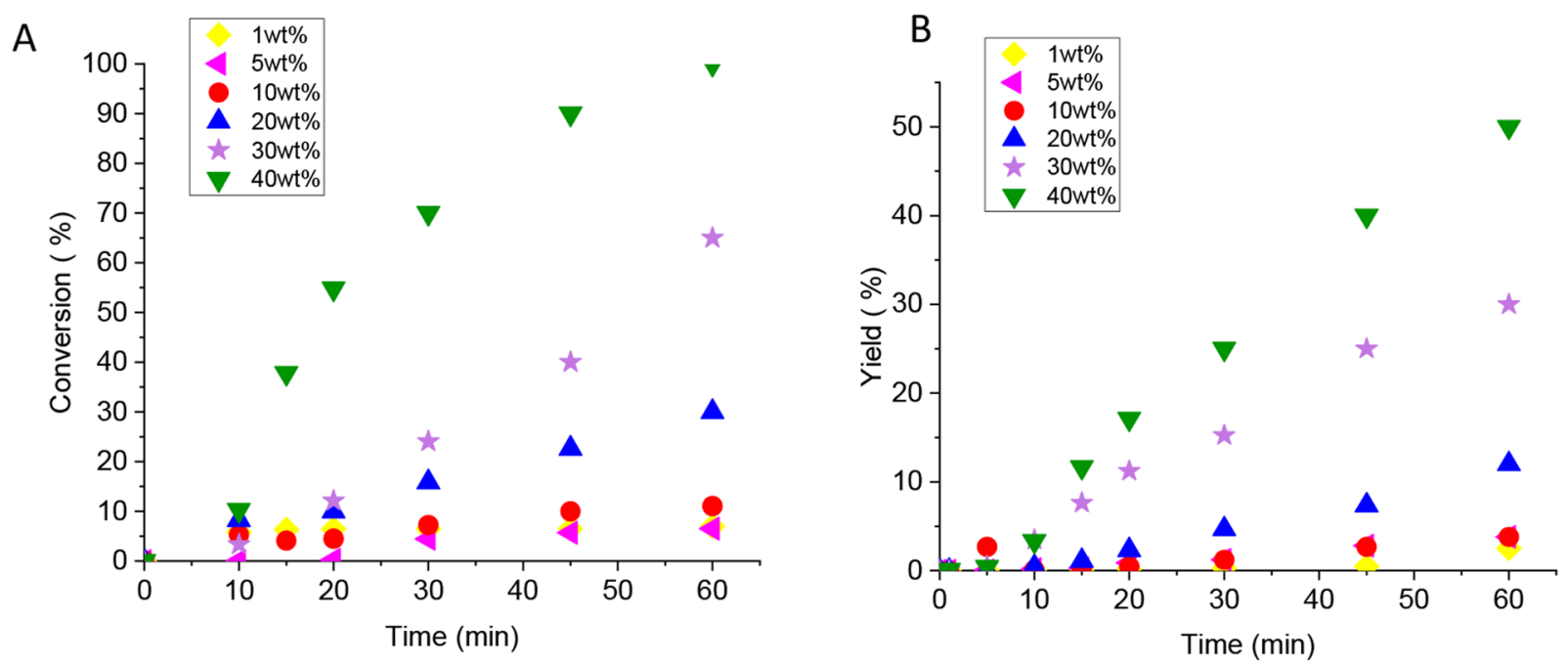

Figure 3. (a) Conversion of xylose and (b) yield of FF as a function of reaction time at $383 \mathrm{~K}$ and six different acid concentrations (1, 5, 10, 20, 30, and 40 wt \%).
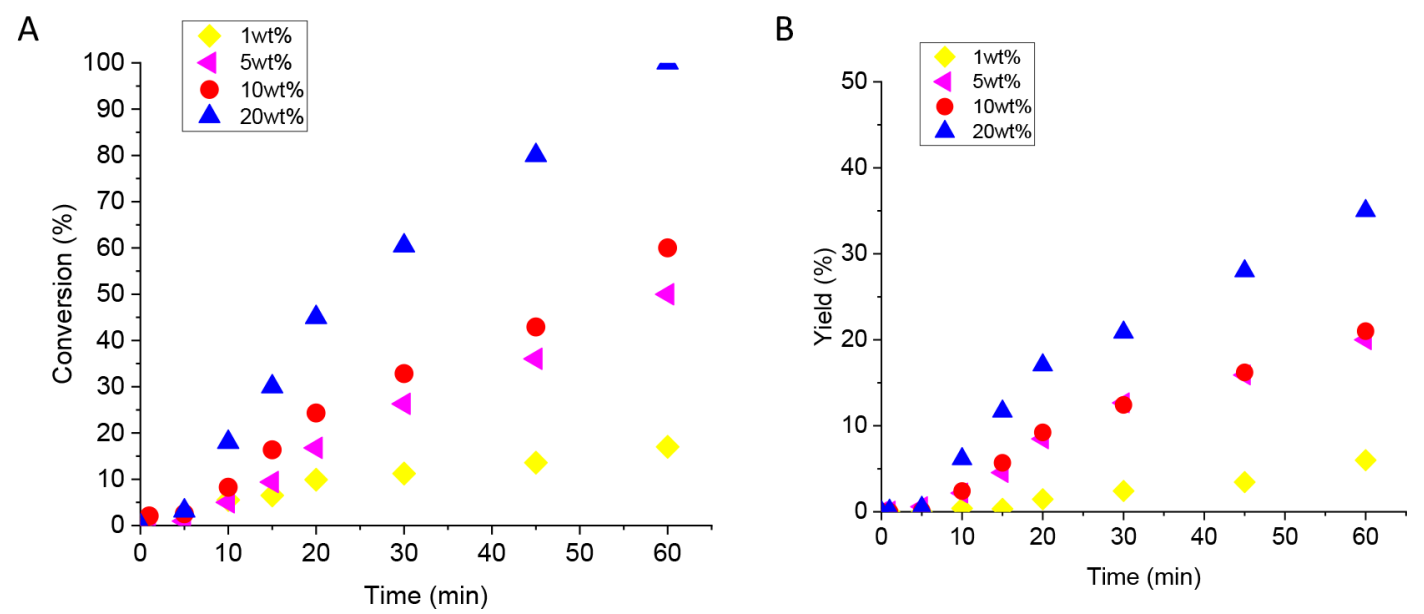

Figure 4. (a) Conversion of xylose and (b) yield of FF as a function of reaction time at $403 \mathrm{~K}$ and four different acid concentrations (1, 5, 10, and 20 wt \%).

and tol. This is the same trend as observed in Table 3. The high yields for $2 \mathrm{sec}$, car, and thy can be explained by the fact that FF will dissolve in these extracting agents and is removed from the reaction mixture. Because the acid stays in the water phase, the FF is no longer in contact with the acid. Therefore, further degradation of the FF is prevented and much higher yields can be obtained compared to the blank experiment (without the presence of any extracting agent).

In the cases in which men or tol are used as in situ extracting agent, the acid is co-extracted together with FF to the organic phase. Thus, FF stays in contact with the acid, and can be further degraded, so the yield is lower (comparable to the blank experiment where FF and acid stay together in the water phase). This is consistent with the results obtained in the section on the degradation of FF in the presence of different extracting agents, where the $\mathrm{pH}$ of the organic phase was found to decrease for tol (benchmark). No other product could be detected with the GC-MS.

The yield obtained for the benchmark tol in our work is much lower than the value reported in the literature $(\sim 50 \%){ }^{27}$ However, we used a much lower solvent-to-feed ratio (molar ratio of $10: 1=$ volumetric ratio of $1.5: 10=1: 6.7)$ as compared to the literature, where a volumetric solvent-to-feed ratio of $2: 1$ was used, which could explain this difference. This indicates that our results for FF yields in the presence of $2 \mathrm{sec}$, car, and thy are remarkably high (three times higher yield compared to the blank and the benchmark) considering the low solvent-tofeed ratios applied.

To validate the results for the yield of FF in the presence of in situ extracting agents, these values were also predicted on the basis of the distribution coefficients obtained in the extraction experiment (without reaction) and the blank reaction experiment (without addition of any extracting agent). The results (both with/without modeling of acid diffusion to the organic phase) are shown in Figure 6A, and in Figure $6 \mathrm{~B}$ the experimental data are included. It can be concluded that the results obtained in the in situ experiments are consistent with the extraction experiments, as the predictions are qualitatively correct. Thus, an FF yield of around $20 \%$ can indeed be expected when a volumetric solvent-to-feed ratio of only $1.5: 10$ is used, and FF yields in the presence of $2 \mathrm{sec}$, car, and thy are indeed very high at the low solvent-to-feed ratios applied in this work. 

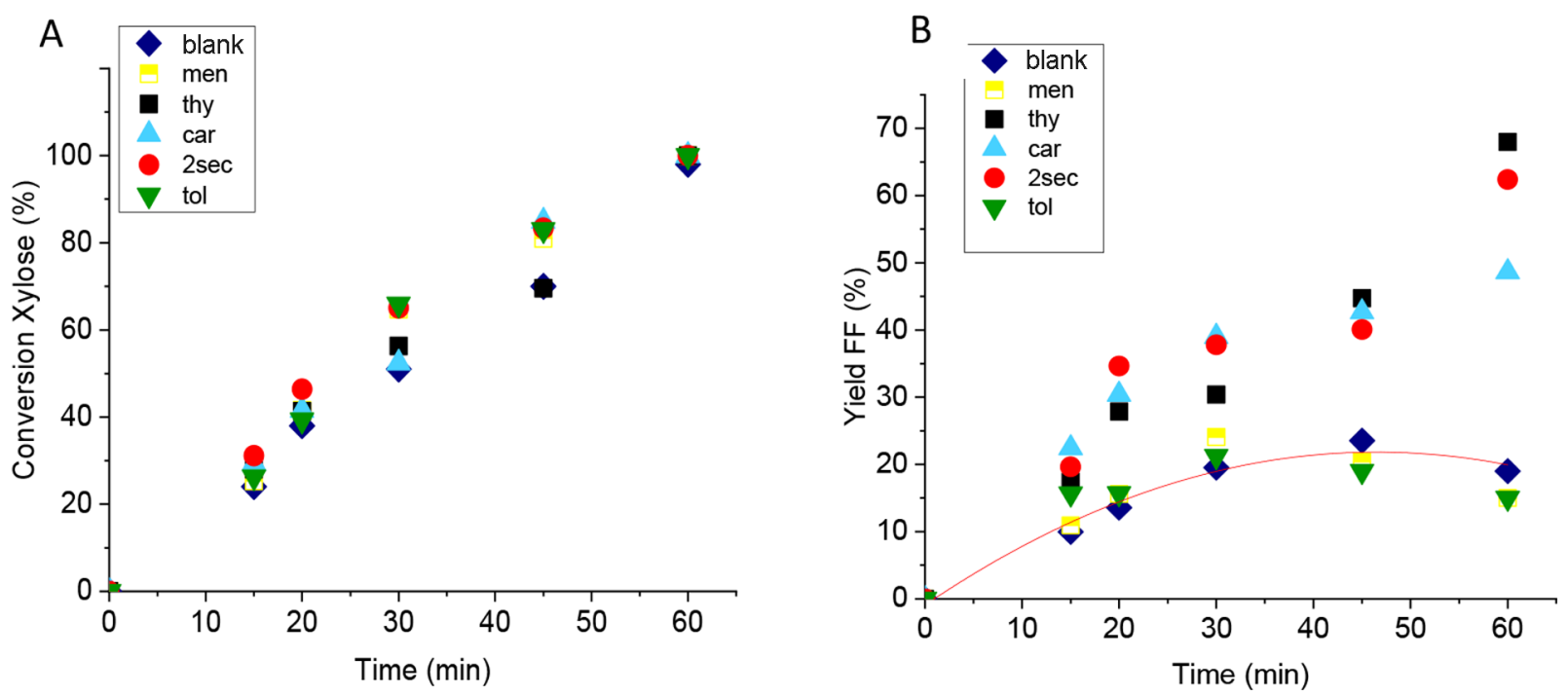

Figure 5. (a) Conversion of xylose and (b) yield of FF as a function of reaction time at $403 \mathrm{~K}$, with 20 wt \% acid, and in the presence of five different in situ extracting agents (car, $2 \mathrm{sec}$, men, thy, and tol) at a solvent-to-feed molar ratio of 10:1. The red line shows the blank experiment (without addition of in situ extracting agent).
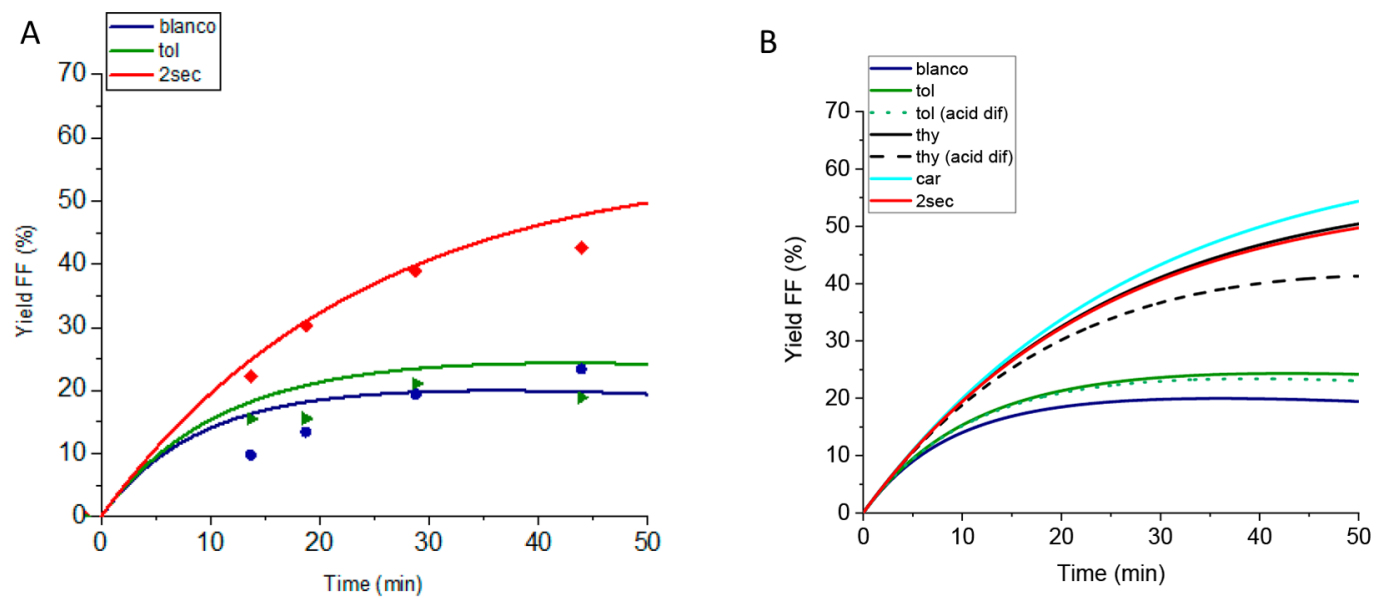

Figure 6. a) FF yield measurements and prediction on the basis of experimentally obtained distribution coefficients (dots) and b) blank reaction experiment without acid diffusion (solid lines) and with acid diffusion (dotted lines) for xylose conversion with in situ extraction of FF using different organic solvents.

\section{Degradation of FF and in Situ Extraction of FF with} Hydrophobic DESs. Four different hydrophobic DESs (i.e., deca-men, deca-thy, thy-lid, and thy-men) were selected as promising bio-based in situ extraction agents on the basis of their viscosity, density, and interaction with $\mathrm{FF}^{28,29}$ First, the effect of the addition of these hydrophobic DESs on the FF degradation was studied by measuring the total concentration of FF in both phases over time and determining the ratio of the amount of FF lost over the initial amount of FF. The results for the degradation of FF in the presence of hydrophobic DESs at a starting concentration of $1 \mathrm{wt} \% \mathrm{FF}, 20 \mathrm{wt} \%$ acid, and a temperature of $403 \mathrm{~K}$ are plotted in Figure 7. In this figure, also the results for the FF degradation in the presence of the organic solvents car and thy at the same conditions are added for comparative reasons.

From Figure 7 it can be concluded that all hydrophobic DESs decrease the degradation of FF in comparison to the blank experiment (without addition of any extracting agent) and the benchmark (toluene, which shows even higher

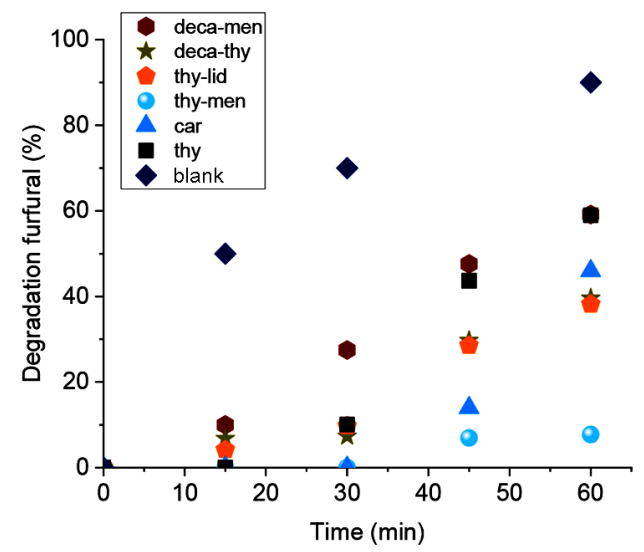

Figure 7. FF degradation (\%) in time at $1 \mathrm{wt} \%$ starting concentration of $\mathrm{FF}$, with $20 \mathrm{wt} \%$ acid, and at $403 \mathrm{~K}$ in the presence of different hydrophobic DESs (deca-men, deca-thy, thy-lid, and thy-men) or organic solvents (car and thy). 
A

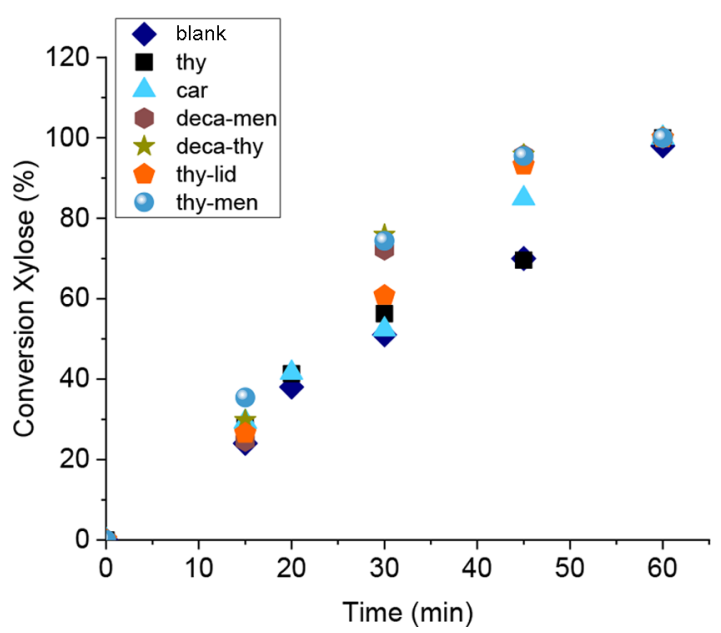

B

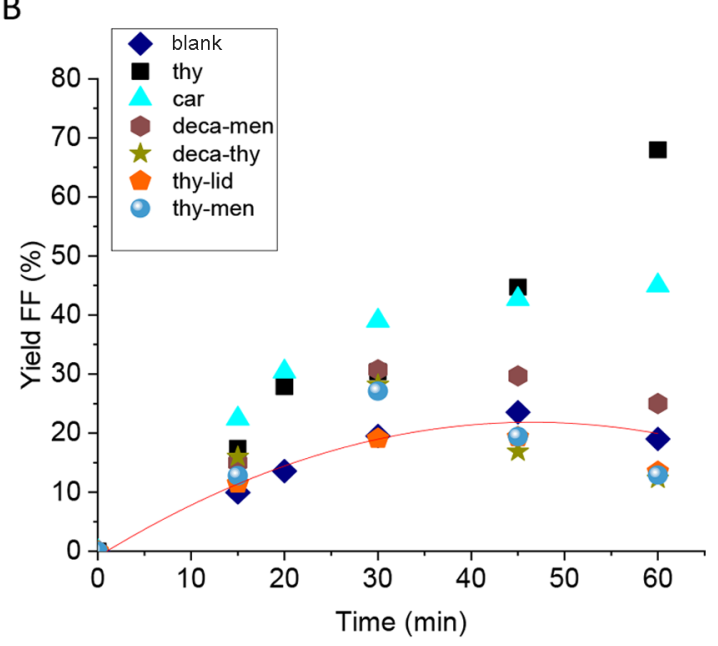

Figure 8. (a) Conversion of xylose and (b) yield of FF as a function of reaction time at $403 \mathrm{~K}$, with 20 wt $\%$ acid, and in the presence of four different hydrophobic DESs (deca-men, deca-thy, thy-lid, and thy-men) and two organic solvents (car and thy) at a solvent-to-feed molar ratio of 10:1. The red line shows the blank experiment (without addition of any in situ extracting agent).

degradation than the blank; see Figure 2). This means that all hydrophobic DESs are able to selectively extract FF from the aqueous phase without co-extraction of the acid, so that the FF is shielded from acid-catalyzed degradation. Thus, all DESs show a similar effect on the FF degradation to the organic solvents car and thy. The best performing DES is thy-men. This hydrophobic DES shows remarkably low FF degradation, comparable to the values observed in systems without any acid present.

Next, the hydrophobic DESs were applied as in situ extracting agents for the removal of FF during xylose conversion at the optimized reaction conditions (4 wt \% xylose, 20 wt $\% \mathrm{H}_{2} \mathrm{SO}_{4}$, and $403 \mathrm{~K}$ ), because of the remarkably low degradation of $\mathrm{FF}$ and the high distribution coefficients. $^{28,29}$ The conversion of xylose and the yield of FF were determined during in situ extraction at a solvent-to-feed molar ratio of 10:1 and are graphically depicted in Figure 8a,b, respectively. Again, results for in situ extraction with the organic solvents car and thy are added for comparative purposes.

First of all, it can be observed that the solvent has almost no influence on the conversion of xylose, which is in agreement with the results shown in Figure 5a. Thus, in all cases, xylose is not extracted to the organic phase but stays in the water phase, where the reaction takes place. Furthermore, it can be noticed that the FF yield (especially in the first $30 \mathrm{~min}$ ) in the presence of hydrophobic DESs is higher than the blank experiment and comparable to the values obtained in the presence of organic solvents. The reason is that the acid is not co-extracted (see Figure 7), preventing further contact between the FF and the acid. However, after $30 \mathrm{~min}$ the FF yields obtained are not further increasing in the presence of the hydrophobic DESs. This cannot be explained by the acid, as it is not co-extracted (see Figure 7). Instead, it may be due to the presence of xylose in the reaction mixture. Xylose can also react with FF and lead to the formation of other side products. However, this is not proven and needs to be further investigated. Still, it should be remarked that it is possible to reach high FF yields (two times higher than the blank experiment) when the hydrophobic DESs deca-men and thy-men are used as in situ extracting agents when the reaction time is limited to $30 \mathrm{~min}$. Thus, hydrophobic DESs are promising in situ extracting agents for the removal of FF from biorefinery processes.

\section{CONCLUSIONS}

The extraction of FF from water and the in situ extraction of FF from its reaction mixture with xylose using different organic solvents and hydrophobic DESs as extracting agents were investigated, as well as the effect of the extracting agent on the FF degradation. The highest distribution ratios of FF were obtained for extracting agents containing a phenol group. Acidcatalyzed FF degradation was decreased when extracting agents were added (as compared to the blank and the benchmark), because all extracting agents showed limited co-extraction of the acid, preventing further contact/reaction between the FF and the acid. The conversion of xylose to FF optimally (highest yield) took place at a starting concentration of 4 wt \% xylose, the addition of $20 \mathrm{wt} \% \mathrm{H}_{2} \mathrm{SO}_{4}$, and a temperature of $403 \mathrm{~K}$. In situ extraction at the optimized reaction conditions using organic solvents and hydrophobic DESs (at a solvent-tofeed molar ratio of 10:1) resulted in comparable xylose conversions but much higher FF yields, compared to the blank experiment. Thus, organic solvents and hydrophobic DESs (especially at short reaction times $<30 \mathrm{~min}$ ) are promising in situ extracting agents for the removal of FF from biorefinery processes.

\section{ASSOCIATED CONTENT}

\section{S Supporting Information}

The Supporting Information is available free of charge on the ACS Publications website at DOI: 10.1021/acs.iecr.9b00694.

Modeling equations used; HPLC and GC chromatograms, calibration curves, and the degradation of FF in time at different acid concentrations, different temperatures, and different extracting agents; yield of FF and conversion of xylose in time at different acid concentrations (PDF)

\section{AUTHOR INFORMATION}

\section{Corresponding Author}

*E-mail: M.v.SintAnnaland@tue.nl. Tel.: +31-402472241. 


\section{ORCID $\odot$}

Maaike C. Kroon: 0000-0002-5985-986X

Maria F. Neira D’Angelo: 0000-0001-8599-2800

Martin van Sint Annaland: 0000-0002-2903-7443

\section{Funding}

Chemelot InSciTe, Project No. 00097, BB.03 (Horizontal project).

\section{Notes}

The authors declare no competing financial interest.

\section{ACKNOWLEDGMENTS}

This work was performed under the framework of Chemelot InSciTe-Horizontal project and with contributions from the European Regional Development Fund (ERDF) within the framework of OP-Zuid and with contributions from the province of Brabant and Limburg and the Dutch Ministry of economic Affairs.

\section{REFERENCES}

(1) Gallezot, P. Process Options For Converting Renewable Feedstocks to Bioproducts. Green Chem. 2007, 9 (4), 295-302.

(2) Naik, S. N.; Goud, V. V.; Rout, P. K.; Dalai, A. K. Production of First and Second Generation Biofuels: A Comprehensive Review. Renewable Sustainable Energy Rev. 2010, 14 (2), 578-597.

(3) Huber, G. W.; Iborra, S.; Corma, A. Synthesis of Transportation Fuels from Bomass: Chemistry, Catalysts, and Engineering. Chem. Rev. 2006, 106 (9), 4044-4098.

(4) Rinaldi, R.; Schüth, F. Acid Hydrolysis of Cellulose as the Entry Point into Biorefinery schemes. ChemSusChem 2009, 2 (12), 10961107.

(5) Faith, W. L. Development of the Scholler Process in the United States. Ind. Eng. Chem. 1945, 37 (1), 9-11.

(6) Kumar, A. K.; Sharma, S. Recent Updates on Different Methods of Pretreatment of Lignocellulosic Feedstocks: a review. Bioresour. Bioprocess. 2017, 4 (1), 7.

(7) Hallett, J. P.; Welton, T. Room-Temperature Ionic Liquids: Solvents for Synthesis and Catalysis. 2. Chem. Rev. 2011, 111 (5), 3508-3576.

(8) Sain, B.; Chaudhuri, A.; Borgohain, J. N.; Baruah, B. P.; Ghose, J. L. Furfural and Furfural-Based Industrial Chemicals. J. Sci. Ind. Res. 1982, 41, 431-438.

(9) Zeitsch, K. J. The Chemistry and Technology of Furfural and Its Many By-products; Elsevier Science, 2000.

(10) Van Grieken, R.; Coto, B.; Romero, E.; Espada, J. J. Prediction of Liquid-Liquid Equilibrium in the System Furfural + Heavy Neutral Distillate Lubricating Oil. Ind. Eng. Chem. Res. 2005, 44 (21), 81068112.

(11) Lecomte, J.; Finiels, A.; Geneste, P.; Moreau, C. Kinetics of Furfuryl Alcohol Hydroxymethylation with Aqueous Formaldehyde over a Highly Dealuminated H-mordenite. J. Mol. Catal. A: Chem. 1998, 133 (3), 283-288.

(12) Hronec, M.; Fulajtárová, K. Terephthalic Acid from waste PET: An Efficient and Reusable Catalyst for Xylose Conversion into Furfural. Catal. Today 2019, 324, 27-32.

(13) Lichtenthaler, F. W. Towards Improving the Utility of Ketoses as Organic Raw Materials. Carbohydr. Res. 1998, 313 (2), 69-89.

(14) Wu, C.; Yuan, W.; Huang, Y.; Xia, Y.; Yang, H.; Wang, H.; Liu, $\mathrm{X}$. Conversion of Xylose into Furfural Catalyzed by Bifunctional Acidic Ionic Liquid Immobilized on the Surface of Magnetic $\gamma$-Al2O3. Catal. Lett. 2017, 147, 953-963.

(15) Wang, Y.; Len, T.; Huang, Y.; Diego Taboada, A.; Boa, A. N.; Ceballos, C.; Delbecq, F.; Mackenzie, G.; Len, C. Sulfonated Sporopollenin as an Efficient and Recyclable Heterogeneous Catalyst for Dehydration of d-Xylose and Xylan into Furfural. ACS Sustainable Chem. Eng. 2017, 5 (1), 392-398.
(16) Yazdizadeh, M.; Jafari Nasr, M. R.; Safekordi, A. A new Catalyst for the Production of Furfural from Biogasse. RSC Adv. 2016, 6, 55778-55785.

(17) Brouwer, T.; Blahusiak, M.; Babic, K.; Schuur, B. Reactive Extraction and Recovery of Levulinic acid, Formic acid and Furfural from Aqueous Solutions containing Sulphuric acid. Sep. Purif. Technol. 2017, 185, 186-195.

(18) Francisco, M.; Van Den Bruinhorst, A.; Kroon, M. C. LowTransition-Temperature Mixtures (LTTMs): A new Generation of Designer Solvents. Angew. Chem., Int. Ed. 2013, 52 (11), 3074-3085.

(19) Lin, L.; Ma, S.; Li, P.; Zhu, T.; Chang, H. Mutual Solubilities for the Water-2-sec-Butylphenol System and Partition Coefficients for Furfural and Formic Acid in the Water-2- sec -Butylphenol System. J. Chem. Eng. Data 2015, 60 (6), 1926-1933.

(20) Delbecq, F.; Takahashi, Y.; Kondo, T.; Corbas, C. C.; Ramos, E. R.; Len, C. Microwave Assisted efficient Furfural Production using Nano-sized Surface-Sulfonated Diamond Powder. Catal. Commun. 2018, 110, 74-78.

(21) Wang, Y.; Delbecq, F.; Kwapinski, W.; Len, C. Application of Sulfonated Carbon-based Catalyst for the fFrfural Production from dXylose and Xylan in a Microwave-assisted Biphasic Reaction. Mol. Catalysis 2017, 438, 167-172.

(22) Soliman, A. B.; Hassan, M. H.; Abugable, A. A.; Karakalos, S. G.; Alkordi, M. H. Post-Synthetic Immobilization of Ni Ions in a Porous-Organic Polymer-Graphene Composite for Non-Noble Metal Electrocatalytic Water Oxidation. ChemCatChem 2017, 9 (15), 29462951.

(23) Trambouze, P.; Euzen, J. Chemical Reactors from Design to Operation; Editions Technip, 2004.

(24) Weingarten, R.; Cho, J.; Conner, W. C., Jr.; Huber, G. W. Kinetics of Furfural Production by Dehydration of Xylose in a Biphasic Reactor with Microwave Heating. Green Chem. 2010, 12 (8), $1423-1429$.

(25) Lide, D. R., Haynes, W. M. M., Baysinger, G., Eds. CRC Handbook of Chemistry and Physics, 2009-2010, 90th ed.; CRC Press: Boca Raton, FL, USA, 2009, p 12862.

(26) Rong, C.; Ding, X.; Zhu, Y.; Li, Y.; Wang, L.; Qu, Y.; Ma, X.; Wang, Z. Production of Furfural from Xylose at Atmospheric Pressure by Dilute Sulfuric Acid and Inorganic Salts. Carbohydr. Res. 2012, 350, $77-80$.

(27) Dietz, C. H. J. T.; Kroon, M. C.; Van Sint Annaland, M.; Gallucci, F. Thermophysical Properties and Solubility of Different Sugar-Derived Molecules in Deep Eutectic Solvents. J. Chem. Eng. Data 2017, 62 (11), 3633-3641.

(28) van Osch, D.; Dietz, C. H. J. T.; van Spronsen, J.; Kroon, M. C.; Gallucci, F.; van Sint Annaland, M.; Tuinier, R. T. A Search for Natural Hydrophobic Deep Eutectic Solvents Based on Natural Components. ACS Sustainable Chem. Eng. 2019, 7 (3), 2933-2942.

(29) Dietz, C. H. J. T.; Gallucci, F.; van Sint Annaland, M.; Held, C.; Kroon, M. C. 110th Anniversary: Distribution Coefficients of Furfural and 5-Hydroxymethylfurfural in Hydrophobic Deep Eutectic Solvent + Water Systems: Experiments and Perturbed-Chain Statistical Associating Fluid Theory Predictions. Ind. Eng. Chem. Res. 2019, 58 (10), 4240-4247. 